\title{
PERANCANGAN ALAT PEMBELAJARAN KUNCI GITAR BERBASIS ARDUINO DAN ANDROID
}

\author{
Astri Simaremare, Haris Tri Saputra, Suwarti \\ Mahasiswa Dan Dosen AMIK Tri Dharma Pekanbaru, Indonesia .
}

\section{INFORMASI ARTIKEL}

Diterima Redaksi: Agustus 2019

Diterbitkan Online: September 2019

\section{KATA KUNCI}

Pembelajaran, arduino uno, android, kunci gitar

\section{KORESPONDENSI}

E-mail:

astrimedlynindryany4@gmail.com,

haristrisaputra@rocketmail.com,

suwarty.atd87@gmail.com

\begin{abstract}
A B S T R A C T
Perkembangan ilmu pengetahuan dan teknologi yang pesat, telah berpengaruh dalam dunia usaha dan memiliki arti penting terhadap kehidupan manusia. Hal ini terlihat dengan adanya berbagai kemudahan yang ditawarkan dan disediakan oleh perusahaanperusahaan. Salah satu perkembangan teknologi saat ini di dunia musik yaitu pada alat musik, dimana penulis ingin merancang sebuah sistem tutorial penggunaan Chord pada alat musik gitar bagi pemula yang ingin belajar memainkan gitar, maka bagi pemula tidak bersusah payah lagi untuk belajar memainkan dan mengetahui Chord pada alat musik gitar, sebab pada alat musik gitar tersebut sudah diletakkan sebuah komponen lampu LED pada masing-masing fred gitar yang terletak dibawah masing-masing senar gitar tersebut.
\end{abstract}

\section{Latar Belakang}

Gitar adalah sebuah alat musik berdawai yang dimainkan dengan cara dipetik, umumnya menggunakan jari maupun plektrum. Gitar terbentuk atas sebuah bagian tubuh pokok dengan bagian leher yang padat sebagai tempat senar yang umumnya berjumlah enam.

Untuk menghasilkan suara gitar yang bagus, kita harus bisa menguasai kunci gitar. Tapi kekurangannya adalah bagi para pemula yang ingin belajar gitar sangat sulit untuk belajar kunci gitar, karna harus melihat buku panduan atau dari internet. Maka dari itu penulis ingin merancang sebuah sistem tutorial penggunaan kunci pada alat musik gitar bagi pemula yang ingin belajar memainkan gitar, maka bagi pemula tidak bersusah payah lagi untuk belajar memainkan dan mengetahui kunci pada alat musik gitar, sebab pada alat musik gitar tersebut sudah diletakkan sebuah komponen lampu LED pada masing-masing fret gitar yang terletak dibawah masingmasing senar gitar tersebut.

Dengan membuka aplikasi Smartphone Android yang dirancang dan dibuat oleh penulis, maka bagi pemula yang ingin belajar mengetahui dan memainkan kunci gitar tersebut hanya tinggal menekan 
tombol button yang sudah diberi label nama kunci gitar pada aplikasi Smartphone Android tersebut, maka masing-masing lampu LED akan menyala dan memberitahu kunci apa yang ingin diketahui dan dicari oleh pemula untuk memainkan alat musik gitar tersebut.

Pada sistem yang dibangun ini penulis hanya membahas :

1. Smartphone Android pada perancangan sistem ini digunakan sebagai Button untuk kunci gitar.

2. Komponen yang digunakan pada sistem ini yaitu LED, Resistor, Arduino Mega 2560, Bluetooth HC 05.

3. LED pada sistem ini berfungsi sebagai Output.

4. Sistem ini hanya memberikan kunci A, B, C, D, E, F, G, Am, Bm, Cm, Dm, Em, Fm, Gm, A\#, B\#, C\#, D\#, E\#, F\#, G\#.

5. Perancangan sistem ini menggunakan software MIT APP Inventor dan Bahasa Pemrograman C.

\section{Kajian Literatur}

\subsection{Arduino Mega}

Arduino adalah platform pembuatan prototipe elektronik yang bersifat open-source hardware yang berdasarkan pada perangkat keras dan perangkat lunak yang fleksibel dan mudah digunakan. Arduino ditujukan bagi para seniman, desainer, dan siapapun yang tertarik dalam menciptakan objek atau lingkungan yang interaktif [1].

Arduino Mega 2560 adalah papan mikrokontroler yang berbasis pada ATmega2560. Ini memiliki 54 pin input / output digital (dimana 15 dapat digunakan sebagai output Pulse Wide Modulation), 16 input analog, 4 UART (port serial perangkat keras), osilator kristal $16 \mathrm{MHz}$, USB koneksi, colokan listrik, header ICSP, dan tombol reset, arduino ini berisi segalanya diperlukan untuk mendukung mikrokontroler, cukup hubungkan ke komputer dengan kabel USB atau diatur dengan adaptor AC ke DC atau baterai untuk memulai. Arduino Mega kompatibel dengan
Shield yang dirancang untuk Arduino Duemilanove atau Diecimila [2].

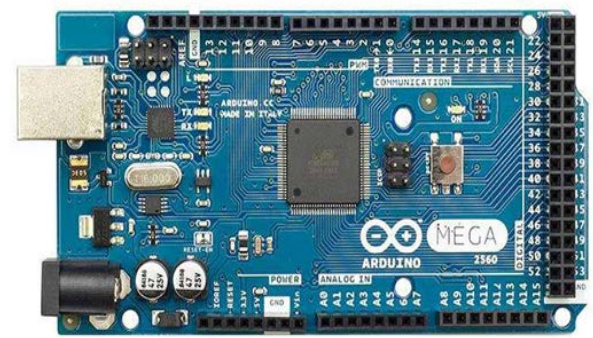

Gambar 1 Tampilan Fisik Arduino Mega 2560

Sumber: Alimuddin (2018)

\subsection{LED}

Light Emitting Diode (LED) adalah komponen elektronika yang dapat memancarkan cahaya. Sesuai dengan namanya, LED adalah salah satu jenis diode. Sebagaimana diketahui, diode adalah komponen yang hanya dapat mengalirkan arus listrik dalam satu arah. Arus listrik hanya mengalir kalau tegangan positif dihubungkan ke kaki yang disebut anode dan tegangan negatif dihubungkan ke kaki yang dinamakan katode. Hal ini berbeda dengan resistor, yang dapat mengalirkan arus listrik walau kedua kakinya dibalik [3].

$$
\text { LED (Light Emitting Diode) }
$$

adalah diode semikonduktor yang memancarkan cahaya monokromatik yang tidak koheren ketika diberi tegangan maju. Jika LED dibias maju, maka arus bias akan menyebabkan diinjeksikannya elektron kedalam bahan tipe-N. Dinyatakan dalam tingkat en ergi, elektron bebas berada pada tingkat yang lebih tinggi dari l ubang. Jika elektron bebas bergerak melalui daerah dekat dengan sambungan, mereka bergabung kembali dalam lubang. Dalam proses penggabungan kembali energi dilepas, sebagian dalam bentuk cahaya dan sisanya dalam bentuk panas. Efisiensi daya keluaran cahayanya sangat rendah, yakni kurang dari 1\% [4].

\subsection{Resistor}

Resistor adalah komponen dasar elektronika yang digunakan untuk membatasi jumlah arus yang mengalir 
dalam satu rangkaian. Sesuai dengan namanya resistor bersifat resistif dan umumnya terbuat dari bahan karbon. Dari hukum Ohms diketahui, resistansi berbanding terbalik dengan jumlah arus yang mengalir melaluinya. Satuan resistansi dari suatu resistor disebut Ohm atau dilambangkan dengan simbol $\Omega$ (Omega). Untuk menyatakan resistansi sebaiknya disertakan batas kemampuan dayanya. Berbagai macam resistor di buat dari bahan yang berbeda dengan sifat-sifat yang berbeda. Spesifikasi lain yang perlu diperhatikan dalam memilih resitor pada suatu rancangan selain besar resistansi adalah besar watt-nya. Karena resistor bekerja dengan dialiri arus listrik, maka akan terjadi disipasi daya berupa panas sebesar W=I2R watt. Semakin besar ukuran fisik suatu resistor bisa menunjukkan semakin besar kemampuan disipasi daya resistor tersebut [5].

Resistor adalah komponen
elektronika yang berfungsi untuk menghambat arus listrik dan menghasilkan nilai resistansi tertentu [6]. ParameterParameter Resistor :

a. Definsi Resistansi Resistor :

1. Besar kemampuan resistor untuk menahan arus listrik,

2. Merupakan nilai resistor dalam ohm yang diukur pada temperatur kerja 25 derajat Celcius.

b. Definisi Power Rating Resistor : Satuan nilai yang menyatakan daya maksimum yang dapat didisipasi secara Kontinyu sampai temperature 70 derajat Celcius.

c. Definisi Toleransi Resistor : Suatu nilai yang menyatakan penyimpangan maksimum yang diperbolehkan/dianggap wajar dari nilai nominal ohm dalam \%.

\subsection{Bluetooth}

Pengertian Bluetooth module merupakan module koneksi nirkabel pada frekuensi $2.4 \mathrm{GHz}$ dengan default koneksi hanya sebagai SLAVE.Module BluetootHini sangat mudah digunakan dengan mikrokontroler untuk membuat aplikasi wireless. Jarak efektif module Bluetooth sebesar 10 meter, meskipun dapat mencapai lebih dari 10 meter tetapi kualitas koneksi akan berkurang [7].

Ada dua jenis bluetooth ke modul serial dengan ganjil dan genap. Bluetooth seri bernomor ganjil sebagai HC-05 atau HC-03 adalah versi perbaikan dari Bluetooth untuk Serial Modul HC-06 atau HC-04. Bluetooth ke serial modul HC-05 dapat ditetapkan sebagai master atau slave perangkat seperti HC-06 modul yang hanya bisa digunakan sebagai Slave [8].

\subsection{Android}

Android adalah sebuah sistem operasi pada handphone yang bersifat terbuka dan berbasis Linux. Android menyediakan platform terbuka (open source) sehingga memudahkan bagi para pengembang untuk menciptakan aplikasi mereka sendiri android awalnya dikembangkan oleh Android, Inc., dengan dukungan Google, yang kemudian android dibeli oleh Google pada tahun 2005 [7].

\subsection{Gitar}

Gitar merupakan salah satu alat musik yang banyak diminati oleh banyak orang terutama bagi anakanak muda, biasanya sebagian besar dari mereka bisa memainkan gitar tanpa mengetahui dasar dari dan teknik bermain gitar. Bagi seseorang yang menggunakan gitar hanya untuk kesenangan tidak akan menjadi masalah, namun lain halnya dengan orangorang yang menekuni musik secara profesional [9].

Menurut peneliti lainnya gitar adalah alat musik berdawai yang dimainkan dengan jari-jemari tangan atau sebuah plektrum (alat petik gitar). Bunyinya dihasilkan dari senar-senar yang bergetar. Gitar berbentuk atas sebuah bagian tubuh pokok dengan bagian leher yang padat sebagai tempat senar yang umunya berjumlah enam didempetkan. Gitar secara tradisional dibentuk dari berbagai jenis kayu dengan senar yang dibuat dari nilon maupun baja [10].

\section{Metodologi}

Kerangka pemikiran dari penelitian ini terdiri dari beberapa langkah yang dapat diliat pada flowchart berikut ini: 


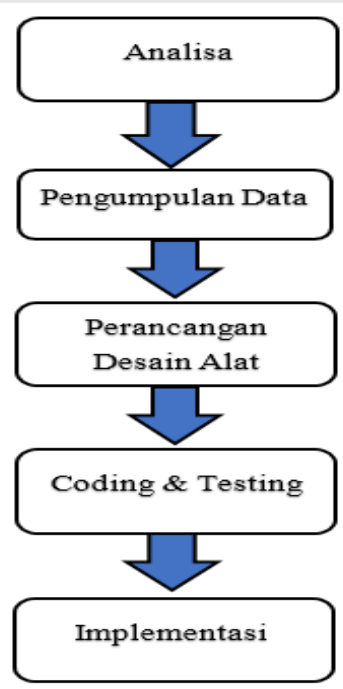

Gambar 2 Flowchart Metode Penelitian

\section{Keterangan :}

\section{Analisa}

Tahap mencari dan mempelajari masalah

yang akan kami teliti. Di tahap ini juga dirincikan ruang lingkup masalah, latar belakang, tujuan dan manfaat penelitian.

\section{Pengumpulan Data}

Tahap peneliti terjun langsung ke lapangan dan mengumpulkan data tentang kunci gitar dari pemain gitar yang menjadi objek penelitian kami.

\section{Perancangan Desain Alat}

Tahap berikutnya adalah merancang dan mendesain arsitektur sistem yang akan digunakan untuk membangun sistem tersebut.

\section{Coding \& Testing}

Pada tahap ini sistem yang sudah dibuat akan diintegrasikan dan di test untuk menguji apakah sistem tersebut telah berfungsi dengan baik dan yang tidak kalah penting adalah sesuai dengan kontrak yang telah disetujui.

\section{Implementasi}

Tahap ini dilakukan untuk menyakinkan bahwa kebutuhan integrasi sistem baru terpenuhi.

\section{Pembahasan}

\subsection{Pengujian Sistem}

Pada bab ini akan dijelaskan langkah-langkah pengoperasian sistem alat pembelajaran kunci gitar menggunakan Arduino berbasis android.
1. Sebelum sistem alat pembelajaran kunci gitar ini digunakan, hubungkan terlebih dahulu kabel power pada catu daya listrik, agar semua komponen yang membutuhkan daya akan teraliri listrik. Gambar pemasangan kabel power dapat dilihat pada gambar dibawah ini :

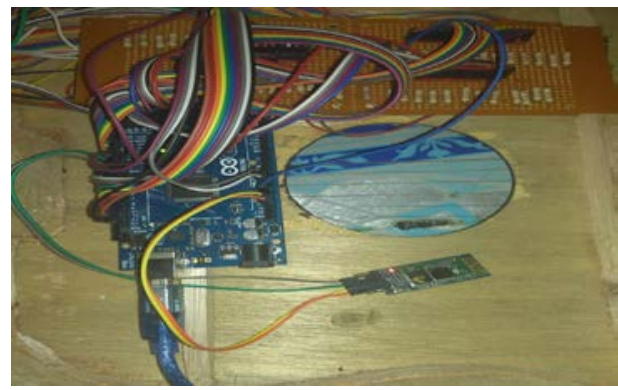

Gambar 3 Cara memasang kabel power

2. Setelah itu koneksikan smartphone dan Arduino dengan menggunakan Bluetooth HC-05, agar dapat memberikan perintah pada sistem alat pembelajaran kunci gitar. Gambar untuk koneksi smartphone dan Arduino dapat dilihat pada gambar 4 .

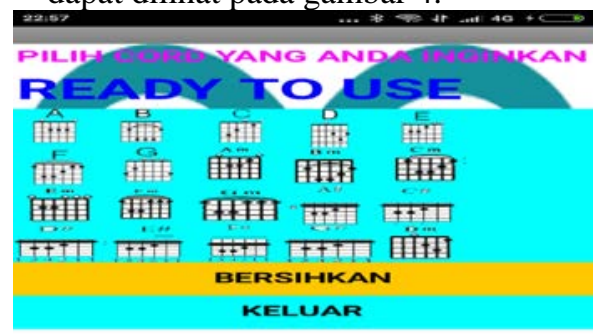

\section{ARDUINO \\ Gambar 4 Koneksi smartphone dan Arduino}

3. Maka langkah selanjutnya adalah proses menjalankan sistem pengontrolan. Untuk menhidupkan Led pada gitar tekan button sebagai perintah yang berisi kunci gitar. 


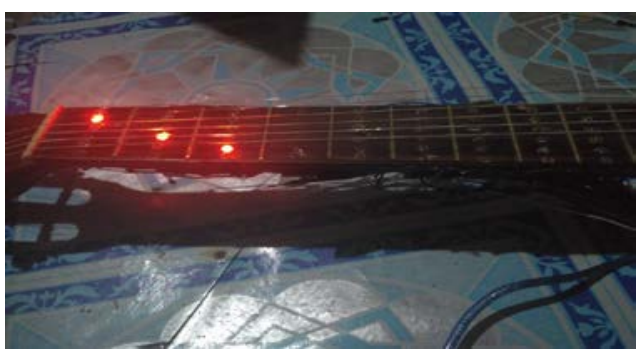

Gambar 5 LED hidup

Dibawah ini adalah tabel hasil pengujian chord gitar:

Tabel 1 hasil pengujian chord gitar

\begin{tabular}{|c|c|c|}
\hline No & $\begin{array}{l}\text { Tombol kunci di } \\
\text { smartphone }\end{array}$ & $\begin{array}{l}\text { Hasil pengujian chord } \\
\text { yang tampil }\end{array}$ \\
\hline 1 & $\frac{A}{n}$ & $\vdots$ \\
\hline 2 & $\frac{B}{1+\infty}$ & : ? \\
\hline 3 & $\frac{C}{i ! n}$ & \\
\hline 4 & $\frac{D}{\min }$ & : \\
\hline 5 & $\frac{E}{\because+1}$ & : : \\
\hline 6 & $\frac{F}{\because ! \ddot{*}}$ & : : \\
\hline 7 & 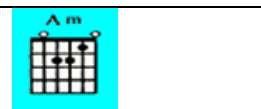 & : : \\
\hline 8 & 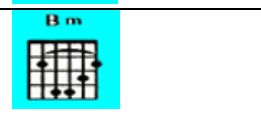 & $1 \vdots: \vdots \vdots$ \\
\hline 9 & 豆㘫 & 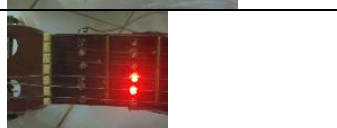 \\
\hline 10 & 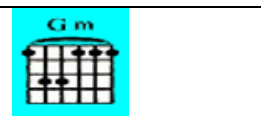 & 10 \\
\hline
\end{tabular}

\section{Kesimpulan}

Berdasarkan pembahasan pada babbab sebelumnya maka pada bab terakhir ini penulis dapat mengambil kesimpulan diantaranya :

1. Untuk mempermudah pemula belajar kunci gitar, maka penulis merancang sebuah sistem alat pembelajaran gitar menggunakan Arduino dan Android untuk menunjukkan kunci gitar tersebut.

2. Sistem alat pembelajaran kunci gitar ini dibuat dengan menggunakan Arduino, dengan output 54 buah Led. Dengan menghubungkan koneksi dengan bluetooth sebagai penghubung antara Smartphone dan Arduino, di Smartphone menggunakan aplikasi yang sudah di pasang terlebih dahulu sebegai kontrol sistem pembelajaran kunci gitar.

\section{Saran}

Dalam sistem alat pembelajaran gitar ini masih terdapat kekurangan, maka saran penulis agar alat ini bisa lebih dikembangkan lagi seperti bisa menyetel tali gitar melalui android dan bisa menghasilkan suara dari kunci gitar.

\section{Ucapan Terima Kasih}

Dalam penelitian ini, kami selaku pihak peneliti ingin berterima kasih kepada pemain gitar yang telah sudi meluangkan tenaga dan waktu untuk membantu peneliti menyeleseikan penelitian ini.

\section{Daftar Pustaka}

[1] J. Arifin, L. N. Zulita, and Hermawansyah, "Perancangan Murottal Otomatis Menggunakan Mikrokontroller Arduino Mega 2560,” J. Media Infotama, vol. 12, no. 1, pp. 89-98, 2016.

[2] Alimuddin, "SISTEM PARKIR CERDAS SEDERHANA BERBASIS ARDUINO MEGA 2560 Rev3," $J$. Electro Luceat, vol. 4, no. 1, pp. 1-12, 2018.

[3] F. Rahmadayanti, “Aplikasi Android Lampu Led Berbasis Arduino,” vol. 09, no. 03, 2016.

[4] Thamin, "Rancang Bangun Alat Pemotong Singkong Otomatis," EJournal Tek. Elektro Dan Komput., vol. 4, no. 1, pp. 29-36, 2015. 
[5] L. Kamelia, Y. Sukmawiguna, and N. U. Adiningsih, "Rancang Bangun Sistem Exhaust Fan Otomatis Menggunakan Sensor Light Dependent Resistor," Tek. Elektro,Fakultas Sains dan Teknol. UIN SGD Bandung, vol. X, no. 1, pp. 154169, 2017.

[6] V. B. D. Dianradika Prasti, "Jurnal Ilmiah d' ComPutarE Volume 2 Juni 2012 Jurnal Ilmiah d ' ComPutarE Volume 2 Juni 2012,” J. Ilm. d'ComPutarE, vol. 2, pp. 1-14, 2012.

[7] D. Muslihudin, "IMPLEMENTASI APLIKASI RUMAH PINTAR BERBASIS ANDROID DENGAN ARDUINO MICROCONTROLLER,” J.
Keteknikan dan Sains, vol. 1, no. 1, pp. 23-31, 2018.

[8] A. Zainuri, U. Wibawa, and E. Maulana, "Implementasi Bluetooth HC - 05 untuk Memperbarui Informasi Pada Perangkat Running Text Berbasis Android,” Eeccis, vol. 9, no. 2, pp. 164-165, 2015.

[9] K. E. Maulana and A. D. Riyanto, "Pembuatan Animasi Interaktif Pembelajaran Gitar Tingkat Pemula ( Interactive Animation Development of Guitar Learning for Beginner ),” Juita, vol. III, pp. 35-41, 2014.

[10] Z. M. Fahri, Rahasia Jago Gitar Otodidak Tanpa Guru: Khusus Untuk Pemula. 2015. 